\title{
Understanding educational conditions in preschool - Preparing student teachers for social justice during practicum placements
}

\author{
Laila Niklasson \\ Mälardalen University, Eskilstuna, Sweden
}

\begin{abstract}
How to cite this paper: Niklasson, L. (2019). Understanding educational conditions in preschool - Preparing student teachers for social justice during practicum placements. The Educational Review, USA, 3(8), 106-112.
\end{abstract}

http://dx.doi.org/10.26855/er.2019.08.003

*Corresponding author: Laila Niklasson, $\mathrm{PhD}$, Professor in education, School of education, culture and communication, Mälardalen University, Eskilstuna, Sweden..

Email: laila.niklasson@mdh.se

\begin{abstract}
The expectations placed on practice teaching in initial teacher education are high. During practice, student teachers should combine theory with practice, make themselves familiar with multicultural classrooms in general, and become aware of different factors that affect learning and teaching. The aim of this study is to increase our knowledge about how work is carried out within practicum placements to help student teachers to understand differing cultural and socioeconomic characteristics of educational settings as a basis for discussing social justice. Staff at practice schools, the practicum team at a university and student teachers were asked about their definitions of different factors that condition learning and teaching, and routines for visiting preschools characterized by different educational conditions. Staff at practice school and university gave examples of different factors, but there was a general lack of organized work with this issue, such as visiting different preschools and holding discussions afterwards. This was confirmed by student teachers, few of whom had visited other preschools and had subsequent discussions. Instead some had experienced variation in work routines, children with special needs and multilingual groups in different sections of their own unit. Experiencing educational environments with different cultural and socioeconomic conditions was considered valuable by the student teachers but was not always given priority. It is concluded that individual variations and needs are understood and formulated by staff and student teachers, but less attention is given to how group belongings and structural frameworks such as socioeconomics are affecting social justice.
\end{abstract}

\section{Keywords}

Teacher Education, practicum, educational factors, social justice

\section{Introduction (Heading 1)}

The aim of this study is to increase our knowledge about how work is carried out during practicum placements to enable student teachers to experience different cultural and socioeconomic conditions affecting children's learning environment in preschools. The background is a trial from 2014 where the practicum component of Teacher Education (TE) was reorganized. The trial was initiated at national level with the aim of increasing the quality of practicum courses. Only schools with teachers who have a combination of relevant subjects and who have participated in a mentorship course are involved. Student teachers are placed in one preschool or school during the practicum but are supposed to visit preschools characterized by other educational conditions than their regular one (SFS 2014:2, p.2; Mälardalens högskola, 2019a, p.9). This is stated in the directives for the trial, and two of a total of three practicum courses have learning goals that include making students aware of the framework for activities. That is, the student teachers are to understand the framework for education on different levels (SFS 2014:2; Mälardalens högskola, 2019, b, c and d).

The knowledge about different educational factors could be related to future capacity to arrange learning-situations in the classroom to address diversity within groups and among individuals, but it can also be related to an awareness of different societal resources and issues around social justice. As Pantic and Florian (2015) argue, teachers are expected to be change 
agents not only in the classroom, but outside it as well. To succeed they need to understand factors outside the classroom that also affect students' learning. An awareness of such factors is needed when discussing democracy and social justice in education. Such awareness can be supported or challenged by national policy acknowledging multiculturalism (David, Phyak and Bui, 2012). On an individual level, student teachers can be more or less open to structural factors affecting educational results (Rose, \& Potts, 2011). Although there are different definitions of the concept of social justice (Mills and Ballantyne, 2016) it can broadly encompass

- a fair redistribution of resources and opportunities,

- recognition of differences,

- the representation of interests in decision making, and development of capabilities to live fulfilling lives.

In this study, it is especially the recognition of factors causing differences in learning environment that is in focus. A starting point for this study is that if student teachers are to be able to participate in discussions about individual or structural factors concerning differences, they need to be aware of, and trained to observe and acknowledge differences in a variety of ways (White and Murray, 2016).

One way of increasing awareness is to visit different practicum preschools and compare the learning environments. The research question of this study concerns how work is carried out during practicum placements to let student teachers experience such differing situations in preschools. The article continues with the context for the case study, examples of earlier studies, presentation of the data collections and the results, and ends with a discussion.

\section{Context}

In Sweden, TE is mainly university based, but the organizers of $\mathrm{K}-12$ education are responsible for organizing practicum placements. Practicum comprises 30 ECTS, divided into practicum periods in all teacher programmes. When the student teachers enter TE, they choose a practice school to visit and practise in. The first and second practicum periods comprise 7.5 ECTS, and the third comprises 15 ECTS for all school forms. Most often, they try to find a practice school not too far from where they live. This make them feel secure during the practicum period but does not always extend their comfort zone. Supervisors from university visit the practice schools and preschools and cooperate with the mentors there. At the TE studied here, student teachers are placed in one preschool or school during the practicum but are supposed to visit preschools with learning environments characterized by other cultural and socioeconomic factors than their regular one (SFS 2014:2, p.2; Mälardalens högskola, 2019a, p.9). The practicum periods are courses with defined contents and learning goals. In the studied $\mathrm{TE}$, it is stated in the course plan of two of three practicum courses that the framework for activities is a learning topic. That is, the student teachers should be aware of the framework on multiple levels (Mälardalens högskola, 2019, b, c and d). The student teachers also follow a Student Guide during the practicum. In the guide, the students must reflect on each learning goal presented in the course plan. In the first course, they shall identify and describe conditions affecting the activities in preschool. In the second course, the framework is not mentioned in the learning goals. In the third course, it is expected that the student teachers should: 'based on deepened subject and preschool didactic knowledge and framework, independently identify, choose and evaluate content and methods, on activity and unit level' (Mälardalens högskola, 2019e).

It can be expected that the differences in the student teachers' experiences will take various forms, whether organizational or structural. On an organizational level, units have different profiles and work in different ways. On a structural level, demographic changes due to migration have increased (OECD, 2015; Acquah, Tandon, \& Lempinen, 2016; Wassell, Reid Kerrigan, Fernandez Hawrylak, 2018). In 2015, there were record numbers of newly arriving children, not only in Sweden but in other countries in Europe as well. Even the USA had a increase in newcomers (Sugarman, 2018). In addition, there are socio-economic differences (Flores and Ferreira 2016) and disadvantages (OECD, 2017). Increased privatization during the last decades has resulted in further differentiation because of free-choice of preschool. Parents may prefer an international approach and not support the local culture, for example by choosing a school where English is the working language (David, Phyak and Bui, 2012). In summary, structural, organizational and pedagogical variety causes situations where one student teacher can experience teaching practice within TE very differently than another.

\section{Earlier studies}

Different factors are discussed from several perspectives in earlier studies, such as changes in demographics with migration, culture, and language, and how this diversity affects educational settings, teaching, and students' learning outcomes. In addition, there are also suggestions of effects of courses during TE. Both diversity and differences are used as concepts in the texts, depending upon the context.

\subsection{Teachers and Teacher Educators}


Some studies focus on perceptions of differences among teachers and teacher educators. As an example of teachers' perceptions, Gorski (2010) studied teachers participating in multicultural courses. An earlier perception that teachers in multicultural courses were mostly concerned with tolerance was not confirmed; instead they were also engaged in critical thinking. However, course curricula showed that courses on multicultural issues did not reflect power, equity and oppression, and teachers tended mostly to choose literature concerning race rather than other identities and forms of oppression.

A later study confirms that issues on societal level are focused upon to a lesser degree. Acquah et al. (2016) studied competencies in culturally and linguistically responsive teaching among in-service teachers in Finland. The results showed that the teachers had limited experience of diversity during their schooling, but some in their current work. They also had little formal training for addressing diversity and wanted more information about cultures, multilingual learners, behaviour, responsibilities, taboos and how to address perceived rude behaviour. To help bridge the achievement gap between students born in the country and immigrants, and to support equity, Acquah et al. (2016) suggest not only in-service training, but also that teacher educators should design pedagogical practices useful for diverse learners. The student teachers must be able to discuss issues of diversity such as racial, ethnic, cultural and linguistic diversity.

The two studies concerning teachers' perceptions showed that they had less interest in issues on a societal level. This could be an effect of it being a course on multicultural issues, or of the questions being about culture and linguistics. As an example of teacher educators' perceptions, Wassell et al. (2018) conducted a questionnaire and interview study about teacher educators' perceptions of diversity in Spain. They found that the teacher educators defined diversity as a broad concept including both internal and external manifestations. Internal manifestations mentioned were beliefs, values and learning preferences. The external manifestations were disability, immigrant status, culture, language, sexual orientation, religion, special needs, social class and contextual or geographical factors. When analysing the data, Wassell et al. (ibid) found that the participants expressed greater tolerance for diversity in their professional contexts than in their personal contexts. The teacher educators directly associated migration with diversity and were interested in an intercultural education approach. On the other hand, when they were asked about future teachers' needs, understanding diversity and being responsive to it were not given priority. However, the teacher educators gave examples of how they worked with diversity in choice of teaching materials and critical discussions. Despite the examples, the findings did not show that the teacher educators addressed, for example, structural and organizational issues or deficit perspectives. It is suggested that it is not enough to understand that there is diversity among learners; this understanding needs to be translated into culturally sustainable pedagogy where diversity is an asset and the norm, and not an 'issue'. It will be an advantage if the teacher educators can become increasingly agentic, rather than reactive, in relation to changes in student population.

Talbot (2011) argues that if a teacher educator is to be able to develop student teachers' cultural competencies, then the educator must also develop such competencies. Summarizing her experiences after a field trip to Malawi, she found that she needed several things: critical reflection when her own assumptions about a teacher's role were challenged (cognition); transformative learning (emotion) when people she encountered treated her in unexpected ways; and a practical community project (hands on), which became a learning situation. Talbot argues that all three dimensions can be helpful and that a classroom approach should be combined with a community approach, as any social injustice has to be addressed on several levels.

\subsection{Student Teachers}

During the TE, different course designs exist to create awareness of diversity. These can include courses on inclusive education, multicultural education and social justice, for example. During most of the TE there are courses in multicultural teaching, sometimes including field experiences aiming to increase cultural awareness and to change stereotypes.

However, not only student teachers and teacher educators have to be aware of diversity. Organizers of TE must also have this insight. Already during TE, there can be a cultural gap between the student teachers and the pupils they will meet, according to Sleeter (2001). The gap arises between white, middle-class teachers who should teach pupils of colour in low-income, urban areas. Therefore, already in the recruitment to TE, there is a need to have awareness of which groups are entering the TE.

In a literature review, Sleeter (2001) found that the results from courses about diversity are mixed; courses do not always increase positive understanding. Even field experiences can result in stereotypes being retained. What seems to function better is more prolonged experience, such as living in a community culturally different from one's own and having opportunities to discuss this experience. In a later literature review, Garmon (2005) found that because student teachers have different backgrounds, it is necessary to start any educational effort by learning about the students' conceptions and experiences. It is especially important because individuals, although they can be grouped, react differently to the educational efforts. An explanation of why the results from courses are mixed may be that the students' dispositions and their experiences both affect the results. These dispositions include level of openness, self-awareness, self-reflectiveness and commitment to social justice. Their experiences include intercultural, educational and support-group experience. Based on these dispositions and experiences, they react differently to the learning situation. 
Some components in TE are especially engaging for students, such as structured field experiences. Sleeter and Owuor (2012) found that education during TE could have an impact on awareness of cultural consciousness. An example is a course where the structure consists of identifying cultural and other strengths of students and identifying patterns of discrimination. At the same time, it can be difficult to integrate multicultural content into the curriculum for both pre-service and novice teachers. Sleeter and Owuor argue that TE still tends to work with cultural awareness but does not go beyond that to develop the skills needed for teaching and being agents of social justice.

A study about attitudes to diversity was conducted by Cardona Moltó, Florian, Rouse and Stough (2010) in Spain, England and the United States. They had students in education respond to a questionnaire about diversity on several dimensions: culture, language, socioeconomic status, social class, religion, gender, sexual orientation, political ideology, disability and special talent. The results showed that the respondents more often chose acceptance as an answer, than tolerance or indifference. Diversity in disability, gender and special talents were more accepted than in political ideology, religion and sexual orientation.

Like Sleeter (2001) and McDonald (2005), Mills and Ballantyne (2010) discuss the need for training when it comes to attitudes towards diversity. They confirm that a single course is not enough and argue that training student teachers' dispositions concerning openness, self-awareness and commitment to social justice must be viewed as a process. In a study, they found that student teachers' reflective texts about their own gendered, raced and classed identities (auto-ethnography) could be sorted by the three mentioned dispositions, and in the suggested order. They also argue that there is a hierarchical development of dispositions, starting with openness, continued with self-awareness and ending in commitment to social justice. Because Mills and Ballantyne argue that there is a development, it is important that there are several courses about diversity during the TE, not only a few single ones. They argue that teacher educators have a special responsibility to support such a design.

Some courses have a focus on social justice. McDonald (2005) studied how two TEs in the United States used different designs to address awareness of social justice. Like Sleeter (2001), she found that earlier studies show that a single course could be less supportive and therefore she examined two TEs with an approach to social justice that lasted throughout the programme. The idea was that the student teachers' learning would be enhanced with a coherent approach during TE. Both TE programmes had the intention to address social justice. Both stated in curriculum documents that discussions should focus on equity and social justice, but one of the TEs was more elaborated than the other. One of the TEs also had a separate course on multicultural issues. First, the findings showed that the student teachers had better opportunities to learn conceptual tools than practical tools. It turned out that there were more opportunities to learn about certain groups than others, that the conceptual tools were favoured, and that practicum placement served as a key mediator in opportunities to learn. When needs were addressed, it was often on an individual level, not raising broader political issues. It was the interaction between a course (conceptual tools) and placement (practice) that supported the student teachers. At the same time, when the students in the study were asked to reflect on whether social justice has been addressed in the TE, it seemed that it was easier for the students also participating in a separate course to recall and reflect on this issue, than for those for whom the issue was integrated into the programme as a whole.

Certain capacities and skills are needed when inclusion and social justice are to be developed. According to Pantic and Florian (2015), the role of the teacher needs to include commitment to social justice, competences to work with others in inclusive pedagogy have to be developed, own agency and power should be acknowledged just as much as the possibility for other actors to reverse exclusion and under-achievement, and finally, capacity to reflect on one's own practice and environment is needed. In the classroom, inclusive pedagogy is more about finding practices suitable for all than arranging special or simplified activities for some. With relational agency, teachers can work with other professionals and later get a broader view of how external structure affects advantage and disadvantage.

In contrast to authors arguing that one course is less effective, Seeberg and Minick (2012) showed that a course during one semester within TE could have some impact. Student teachers in the USA with limited foreign culture experience got in contact with students from Mexico and Native Americans. They discussed textbooks from the USA and Mexico presenting the same event and found that the US textbook was more biased. They also had dialogues about perceptions of each other. In the end, the students developed their knowledge about other cultures, interaction skills and skills in using video for dialogue. Whether this knowledge and these skills can persist during service as a teacher is an open question.

Finally, student teachers also have an opportunity to study abroad and thereby experience another culture. Marx and Moss (2011) have studied a study-abroad programme and argue that to be culturally responsive, student teachers must become culturally conscious and inter-culturally sensitive. It is not always enough to place student teachers in schools with culturally diverse students to create awareness of sociocultural dynamics. The student teachers need to personally experience being 'culturally different'. Marx and Moss followed a student teacher from the USA who studied and worked in England for a semester. The study abroad was part of the TE in the USA and included working in school, studies and meetings for reflection arranged by a cultural translator (a teacher). The findings showed that after completion of the semester abroad the student teacher had to a certain extent overcome the key aspects of an ethnocentric worldview, denial of cultural difference and defence of one's own viewpoint, and was instead approaching an ethno-relativistic worldview, with acceptance, adaptation and integration (Bennet, 
2004). The student's first impressions of 'bad teaching' could be changed to 'another way of teaching', grasping differences in another society's understandings of childhood, adult-child relations and philosophies of education. The education systems in the USA and England may look similar, but it turned out that there were differences that made the student teacher feeling like a cultural outsider. In this case, the student teacher could not rely on the majority culture, as in USA, but had to interpret the new situation.

In summary, several studies have shown that teachers, teacher educators and students have some awareness of diversity. This awareness may be expressed as acceptance or tolerance and does not necessarily serve as a ground for agency aiming at social justice. Some types of diversity, such as race, are addressed more than others, but even though race can be linked to structural issues, the structural level seems to get less attention. There are mixed results from courses. Some yield better results when diversity is directly addressed; in other circumstances it is better addressed when integrated into other courses over several semesters. The conclusion from the presentation of earlier studies is that there is a need to study and discuss diversity on different levels: individual, group and structural. One way of doing this is to make sure that student teachers experience preschools and schools with different educational environments and can discuss and reflect about their experiences with mentors.

\section{Data collection}

The study reported here is an exploratory study. There are three categories of respondents: staff at practicum school, student teachers and staff at university. Three data collections were carried out. All data collections complied with the standard ethical guidelines used in Swedish contexts. Potential participants received information about the study and were informed that they could decline to participate and that the results would be presented on a group level (Vetenskapsrådet [Swedish Research Council], 2011).

An initial data collection was carried out with contact persons at the central organizational level for organizers of K-12 education in the region. The practicum team at the university arranged regular meetings with them, and during such meetings the author presented the study. About ten people from different school forms (preschool, compulsory school and uppersecondary school) were possible to reach at that meeting. The organizers mainly represented public schools, but there were also some from private schools. Two questions were asked. The first concerned how they defined 'different educational conditions', and the other whether their school had a model for student teachers visiting units characterized by 'different educational conditions'. The discussion was documented by taking notes.

We decided to focus on the representatives of the preschool programme, as they were the first cohort to complete the reorganized practicum placements. They graduated in January 2018. In addition, one organizer, a mid-size municipality, was chosen, as I was informed that they had a model for visiting other preschools. There were eight public practice preschools units and three private ones. Within a unit, there can be several preschools, and the preschools are in turn divided into sections.

A second data collection was carried out among contact persons at preschool units. They received an e-mail with questions that they could choose to answer directly by e-mail or by telephone later. Some replied directly by e-mail, while others preferred to be contacted by telephone. In total, nine contact persons at unit level were possible to reach. Among them, one preschool unit was private. They were asked the following questions. The first concerned in what ways they had discussed 'different conditions' in general with the student teachers, the second whether they had presented any special profile at the unit or special cultural or socioeconomic factors affecting education at the unit, and the third whether they had any model for letting the student teachers visit units characterized by other conditions. The e-mails had written answers; the telephone interviews were documented by taking notes.

Based on the results from the two data collections and earlier literature, a set of questions was formulated for student teachers in the Preschool programme. The first question concerned whether the staff told the student teachers about any profile or special conditions; then they were asked to describe the unit. After that, they were asked about visits, and whether they were made at their own or the supervisor's initiative. They were also asked whether there was a model for visiting other units, and if differences in educational conditions were discussed during the practicum. The contact data for student teachers was received from the administrator responsible for practicum placements and one of the practicum coordinators at the university. From the lists of student teachers, it was possible to identify 31 student teachers who had completed all three practicum courses and whose contact data, including home address, telephone number and e-mail address, was in the database. Just before they ended the programme, an e-mail was sent to all of them with a presentation of the study and clarification of the ethical guidelines (Vetenskapsrådet, 2011). After their graduation, a first telephone call was made. The data collection then continued for a few months and a written letter was sent to their home addresses as a reminder about the study. The remaining student teachers were called again. Of the 31 teacher students, it was possible to reach twelve. All answers from the telephone interviews were documented by taking notes.

The reading of the material involved three challenges: sorting, reduction and argumentation (Rennstam and Wästerfors, 
2015). As all respondents received two main questions, concerning perception of factors affecting the learning environment and routines for visiting other units, and the comparing of factors. The sorting of the material for presentation focused on tracing answers to these questions. All notes and e-mail answers from the respondents were read and re-read several times. The answers from the three groups of respondents were treated as three different units of texts when reading the material. At the end, the material was summarized, a kind of reduction, on a group level for two different groups of staff and for the group of students. The summary of the material aims at capturing the picture the respondents present. The discussion section at the end uses the summaries when presenting arguments for our claim that knowledge about, and problematization of cultural and socioeconomic factors is vital for discussing teachers' role and agency, both in the classroom and in society.

The claims made in this study are limited. Because the dialogues with all three groups of respondents were short, and no regular, longer, booked interviews were carried out, the study contributes an initial exploratory presentation of how differing educational conditions are dealt with during TE for preschool teachers. No claim is made that the picture presented can be transferred to all TE programmes for preschool or other school forms. Further follow-up studies are needed, preferably with regular interviews, observations, and reading of the student teachers' Student Guides where they write about their practicum.

\section{Results}

\subsection{Staff}

Results from the first data collection showed that contact persons (mostly teachers) from organizers of K-12 education (municipalities as well as private companies) in two counties suggested a broad definition of factors affecting the educational environment, organizational as well as social. They mainly talked about linguistic diversity, routines for activities and differences between preschool (for children 1-5 years old) and preschool class (6 years). Their understanding was that there were few models or routines for whether the student teachers experienced different situations or mostly stayed at one unit. Some contact persons have begun to create a model; for others this was a new issue in 2017 (despite the trial having started in 2014). In summary, a few examples of diversity were given, and the impression was given of a lack of routines for visiting other units.

Results from the second data collection showed that contact persons from unit level (teachers) in one municipality confirmed that differences could be organizational, such as experiences of different age groups or pedagogical methods, and visiting preschool class, as well as social, such as experiences of multi-language groups or whether families are supported by welfare benefits. There are examples of a perception that each child should be recognized as an individual and not grouped into categories (language groups, etc.) in contrast to a perception that socio-economic factors are clearly visible, and that children can be discussed in terms of perceived group belongings. There were no comments regarding any clear perception of structural issues other than welfare benefits. Few examples were given of routines for visits, other than that the student teachers were helped to visit preschool class. It was commented that the student teachers often visit different sections at a unit, and can thereby notice differences. In summary, examples were given of differences, but not evidence that student teachers always experienced learning environments characterized by different conditions.

A preliminary conclusion from the first two data collections is that there was awareness of different factors conditioning the learning environment, but no clear agenda or routines for how student teachers experience or should experience environments with different conditions. Even though the learning goals include these issues, no reference was made to them by staff.

\subsection{Student Teachers}

A third data-collection was carried out among student teachers. Their answers could be sorted into discussions about educational conditions, perceptions of educational conditions, actual experienced educational conditions and general thoughts about educational conditions.

Often there was no presentation or discussion of different learning environments at the beginning of the practicum. Usually the staff did not describe any special profile or vision for the unit at the beginning; they successively described different aspects of 'how things were done'. After a while, the mentors discussed and compared their work in other units with the student teachers. All the teacher students perceived that experience of learning environments conditioned by different factors can be useful and necessary, but that it was not always their priority. A few had friends that visited preschools abroad and regretted that they did not take the chance to go abroad. In contrast, some of them did not want to leave the unit/section. One reason for this was that it takes time to build trust between the student teacher and the children; other reasons were that they thought that the mentors were good, and that the learning environment was good. If they were to visit another preschool for a short period of time, it would be hard to do their job in the new environment due to a lack of trust from the small children.

The general perception was that there usually was no routine or model for having a chance to experience differences; it depended on discussion, negotiation and interest from the student teacher. Nevertheless, most of them visited a preschool class. 
They had also experienced linguistic diversity. This experience mostly came from their own units/sections, or occurred during visits to another unit. Most of them had experienced differences in working routines, attitudes toward, and ways of engaging with the children, mostly in their own units/sections. Parental engagement also differed, which was mostly experienced in their own units/sections. Some had experienced special education needs, mostly in their own units/sections or when visiting others. During the practicum, most of them had participated in discussions in the unit/section about differences, mainly concerning working routines.

The student teachers often had their placement at a preschool near their home. Most were in areas with a combination of better and worse socio-economic conditions among the families. Few of the respondents referred to learning environments characterized by socio-economic diversity, or elaborated on structural issues; nor did they mention or discuss differences between urban and rural areas.

In summary, because a preschool unit includes several sections most of the student teachers were able to visit several sections. This enabled them to experience varying work routines, linguistic diversity and differences in parental engagement. Because preschool teachers in Sweden are also certified to work in preschool classes, most also visited a preschool class. On the other hand, only some of them had experienced children with special needs, and even though there were discussions about differences, the discussions mostly concerned organizational issues like work routines, and not actual educational factors like socio-economic status or cultural differences. No reference was made by teachers to the content or the learning goals of the practicum courses in the Student's guide for practicum.

\section{Discussion}

The aim of this study has been to increase our knowledge about how work is carried out within practicum courses to help student teachers to understand variations in factors conditioning educational settings as a basis for discussing social justice.

The result showed that staff in charge of practicum courses were aware of different educational conditions in preschools but had less of a clear agenda or routines when it comes to how student teachers should be enabled to experience different educational conditions. The different conditions that were most often mentioned were whether several languages were spoken in the classroom and whether there were children with special needs, which is in accordance with earlier studies (Acquah et al., 2016; Wassell et al., 2018). Otherwise staff mainly mentioned organizational or pedagogical issues like routines for activities, different age groups and differences between preschool and preschool class. The socio-economic issue mentioned was whether families were supported by welfare benefits. The students mentioned most of all linguistic diversity and special education needs. Just like the staff, they mentioned organizational and pedagogical issues like working routines and staff attitudes toward, and engagement with children, and differences between preschool and preschool class. They also mentioned that parental engagement differed. In general, the student teachers did not reflect on structural issues to any greater extent, nor did staff or students refer during the practicum courses to the content and learning goals concerning understanding the framework for activities.

The staff mentioned few explicit routines for enabling students to experience diversity, other than visiting preschool class. The students did not do so either. The results show a focus on daily activities and how the children should be taken care of and taught. Organized discussions between mentors and student teachers about structural issues and social justice seem to be less frequent. The support for experiencing different cultural and socioeconomic conditions in educational settings was therefore limited.

Our conclusion is that the respondents discuss and experience diversity as an individual and organizational issue. There is a recognition of differences (Mills and Ballantyne, 2016), but in this study diversity is mostly limited to language and special needs, in combination with organizational and pedagogical issues. Teachers appear to be expected to function as change agents in the classroom (Pantic and Florian, 2015) rather than engaging with factors outside the classroom. As there is no assessment on individual level in preschool, the mentors and student teachers do not discuss structural factors that may affect individual educational results, as is done in other school forms (Rose and Potts, 2011). Therefore, possible links between individual results, group belongings and structural factors are not what teacher educators or student teachers think of.

Based on the earlier studies and the findings, some suggestions can be made. There are several possible ways to support the link between the classroom and social justice issues. A first suggestion is to create situations where the role of teachers is discussed and to open up for a change-agent role beyond the classroom. If the teacher educators are to be trustworthy then there are some suggested prerequisites. First, it is necessary to clarify two different roles: the role of the citizen and the role of the professional. A similarity is that they both must make their statements public in one way or another; a difference is that a citizen acts as an individual, whereas a teacher claims to have a group, a profession, to relate to. The similarities and differences are an open question and can be problematized. At least in the history of the teaching profession in Sweden, it is not hard to find teachers who have been change agents and politically engaged both locally and nationally. They were involved, for example, in extending the length of compulsory school and reforming teacher education (Florin, 2019). However, it seems to be easier to document teachers as change agents during the $19^{\text {th }}$ and early $20^{\text {th }}$ centuries than during the late $20^{\text {th }}$ century (Carlgren, 2019). From having been perceived as change agents, teachers are now regarded as moderators or coaches supporting the pupils in 
adapting to changes (Lindberg, 2005). Whatever stance the teacher educators take, they have a chance to bring themselves into the discussion and clarify their own opinions in a dialogue with the student teachers. Then they can give examples of situations and fora where it is possible to discuss. The suggested activities presuppose that teacher educators themselves understand local and national rules for political action. The suggestions are primarily concerned with the question of how to act. What to act upon and critically discuss depends on the context.

To conclude, if student teachers are to be able to participate in discussions about individual or structural factors, they need to be aware of, and trained to observe and acknowledge differences, as White and Murray argue (2016). This awareness presupposes that teachers at university and mentors at practicum schools are aware of conditions creating differences and are open for discussions about social justice.

\section{Acknowledgements}

The research was partly funded by Mälardalen University.

\section{References}

Acquah, O. E., Tandon, M., \& Lempinen, S. (2016). Teacher diversity awareness in the context of changing demographics. European Educational Research Journal, 15(2), 218-235.

Allard, A. \& Santoro, N. (2006). Troubling identities: teacher education students' constructions of class and ethnicity. Cambridge Journal of Education, 36(1), 115-129.

Bodur, Y. (2012). Impact of course and fieldwork on multicultural beliefs and attitudes. The Educational Forum, 76(1), 41-56.

Cardona Moltó, M. C., Florian, L., Rouse, M., \& Stough, L. M. (2010). Attitudes to diversity: a cross-cultural study of education students in Spain, England and the United States. European Journal of Teacher Education, 33(3), $245-264$.

Carlgren, I. Lärarna i kunskapssamhället [Teachers in the knowledge society]. Available http://www.lararnashistoria.se/sites/ www.lararnashistoria.se/files/artiklar/Lärarna i kunskapssamhället_0.pdf

Clarke, M. \& Drudy, S. (2006). Teaching for diversity, social justice and global awareness. European Journal of Teacher Education, 29:3, 371-386.

David, A. K., Phyak, P., \& Bui, N. T. T. (2012). Multicultural Education as Community Engagement: Policies and Planning in a Transnational Era. International Journal of Multicultural Education, 14(3), 1-25.

Flores, A. M. \& Ferreira, I. F. (2016). Education and child poverty in times of austerity in Portugal: implications for teachers and teacher education. Journal of Education for Teaching. International research and pedagogy. 42:4, 404-416.

Florin, C. Lärarnas professionalisering [Teacher Professionalization]. Available 20190122, http://www.lararnashistoria.se/sites/ www.lararnashistoria.se/files/artiklar/Lärarnas professionalisering_0.pdf

Garmon, M. A. (20015). Six key factors for changing preservice teachers' attitudes/beliefs about diversity: what are the critical factors? Journal of Teacher Education, 55(3), 201-213.

Goodwin, A. L., Smith, I., Souto-Manning, M., Cheruvu, R., Tan, M. Y., Reed, R. \& Taveras, L. (2014). What Should Teacher Educators Know and Be Able to Do? Perspectives from Practicing Teacher Educators. Journal of Teacher Education, 65(4), 284-302.

Gorski, C. P. (2010). The Scholarship Informing the Practice: Multicultural Teacher Education Philosophy and Practice in the United States. International Journal of Multicultural Education, 12(2), 1-22.

Gustafsson, B. \& Österberg, T. (2016). How are Immigrant Children in Sweden Faring? Mean Income, Affluence and Poverty Since the 1980s. Child Indicators Research, DOI 10.1007/s12187-016-9416-9.

Lindberg, O. (2005). Vad är det för mening med lärarna? [What is the use of teachers?]. Pedagogiska magasinet 1. Available 20190122, https://pedagogiskamagasinet.se/vad-ar-det-for-mening-med-lararna/.

Marx, H. \& Moss, D. M. (2011). Please mind the culture gap: Intercultural development during a teacher education study abroad programme. Journal of Teacher Education, 62, 35-47.

McDonald, M. A. (2005). The integration of social justice in teacher education: dimensions of prospective teachers' opportunities to learn. Journal of Teacher Education, 56(5), 418-435.

Mills, C. \& Ballantyne, J. (2016). Social Justice and Teacher Education: A Systematic Review of Empirical Work in the Field. Journal of Teacher Education, 67:4, 263-276 
Mälardalens högskola (2019a). VFU-handbok för lärarutbildningen vid Mälardalens högskola [Practicum handbook for the teacher programme at Mälardalen University]. Available 20190111, https://vfu-ukk.mdh.se/documents/malardalenukk/ documents/handbok\%20vfu\%20\%20vt2019.pdf

Mälardalens högskola (2019b). Supervised placement, part 1, for teachers in preschool, 7,5ECTS. Available 20190111, https:// www.mdh.se/utbildning/kurser/kursplaner-1.35552?benamning=\&kurskod=OAU193\&niva=\&huvudomrade=\&fordjupning=\& akademi $=\&$ search $=\mathrm{S} \% \mathrm{C} 3 \% \mathrm{~B} 6 \mathrm{k} \#$

Mälardalens högskola (2019c). Supervised placement, part 2, for teachers in preschool, 7,5 ECTS. Available 20190111, https:// www.mdh.se/utbildning/kurser/kursplaner-1.35552?benamning=\&kurskod=OAU198\&niva=\&huvudomrade=\&fordjupning=\& akademi $=\&$ search $=\mathrm{S} \% \mathrm{C} 3 \% \mathrm{~B} 6 \mathrm{k} \#$

Mälardalens högskola (2019d). Supervised placement, part 3, for teachers in preschool, 15ECTS. Available 20190111, https:// www.mdh.se/utbildning/kurser/kursplaner-1.35552?benamning=\&kurskod=OAU202\&niva=\&huvudomrade=\&fordjupning=\& akademi $=\&$ search $=\mathrm{S} \% \mathrm{C} 3 \% \mathrm{~B} 6 \mathrm{k} \#$.

Mälardalens högskola (2019e). Studenthandbok för Verksamhetsförlagd utbildning [Student guide for practicum]. Available 20190407, https://vfu-ukk.mdh.se/documents/malardalenukk/documents/studentbok\%20ht18_2.pdf.

OECD (2015). PISA in Focus: Can the performance gap between immigrant and non-immigrant students be closed? Paris. Available 20181227 at https://www.oecd-ilibrary.org/education/can-the-performance-gap-between-immigrant-and-nonimmigrant-students-be-closed_5jrxqs8mv327-en

OECD (2017). PISA in Focus: How do schools compensate for socio-economic disadvantage? Paris. Available 20181227 at https://www.oecd-ilibrary.org/education/how-do-schools-compensate-for-socio-economic-disadvantage_a77ee9d5-en

Pantic, N. \& Florian, L. (2015). Developing teachers as agents of inclusion and social justice. Education Inquiry, 6:3, 27311, DOI: $10.3402 /$ edui.v6.27311

Rennstam, J. \& Wästerfors, D. (2015). Att analysera kvalitativt material [Analysing qualitative material]. In Göran Ahrne \& Peter Svensson (Eds.). Handbok $i$ kvalitativa metoder [Manual in qualitative methods], 220-236. Stockholm: Liber.

Reynolds, R. \& Brown, J. (2010). Social justice and school linkages in teacher education programmes. European Journal of Teacher Education, 33:4, 405-419.

Rose, G. D. \& Potts, D. A. (2011). Examining Teacher Candidate Resistance to Diversity: What Can Teacher Educators Learn? International Journal of Multicultural Education, 13(2), 1-19.

Santoro, N. \& Forghani-Arani, N. (2015). Interrogating practice in culturally diverse classrooms: what can an analysis of student resistance and teacher response reveal? European Journal of Teacher Education, vol 38:1, 58-70.

Seeberg, V. \& Minick, T. (2012). Enhancing Cross-cultural Competence in Multicultural Teacher Education: Transformation in Global Learning. International Journal of Multicultural Education, 14(3), 1-22.

SFS 2014:2. Förordning om försöksverksamhet med övningsskolor och övningsförskolor inom lärar- och förskollärarutbildningar [Regulation on trials with practice schools and practice preschools within teacher- and preschool teacher programmes]. Stockholm.

Sleeter, E. C. (2001). Preparing teachers for culturally diverse schools. Research and the overwhelming presence of whiteness. Journal of Teacher Education, 52:2, 94-106.

Sleeter, C. E. \& Owuor, J. (2011). Research on the impact of teacher preparation to teach diverse students: The research we have and the research we need. Action in Teacher Education, 33, 524-536.

Sugarman, J. Meeting the Education Needs of Rising Numbers of Newly Arrived Migrant Students in Europe and the United States. Migration Policy Institute. Retrieved March 25, 2018, https://www.migrationpolicy.org/news/meeting-education-needsrising-numbers-newly-arrived-migrant-students-europe-and-united-states

Talbot, A. P. (2011). Aha Malawi! Envisioning Field Experiences that Nurture Cultural Competencies for Preservice Teachers. International journal of Multicultural Education, 13(1).

Wassell, A. B., Kerrigan Reid, M., \& Fernandez Hawrylak, M. (2018). Teacher educators in a changing Spain: Examining beliefs about diversity in teacher preparation. Teaching and Teacher Education, 69, 223-233.

White, L. M. \& Murray, J. (2016). Seeing disadvantage in schools: exploring student teachers' perceptions of poverty and disadvantage using visual pedagogy. Journal of Education for Teaching. International research and pedagogy. 42:4, 500-515. 